\title{
JRODOS: Platform for improved long term countermeasures modelling and management
}

\author{
W. Raskob ${ }^{1}$, D. Trybushnyi ${ }^{1}$, I. levdin ${ }^{2}$ and M. Zheleznyak ${ }^{2}$ \\ ${ }^{1}$ Karlsruhe Institute of Technology, Institut für Kern- und Energietechnik, \\ Eggenstein-Leopoldshafen, Germany \\ ${ }^{2}$ Ukrainian Center for Environmental and Water Projects (UCEWP), Glushkova 42, \\ 03187 Kiev, Ukraine
}

\begin{abstract}
One of the major objectives of the $6^{\text {th }}$ Framework EC RTD EURANOS (European Approach to Nuclear and Radiological Emergency Management and Rehabilitation Strategies) project was to improve the RODOS (Real-time on-line decision support) system in its operational applicability. In the first phase of the project two possibilities for the main system development has been discussed: either to carry out refinements in the current version of RODOS or to consider a complete software re-engineering. The RODOS Users Group (RUG) finally concluded that the latter option was one to be realised. As a result a JAVA based version named JRODOS has been developed introducing a cross-platform solution capable to run on most operation systems, including Windows, Macintosh and the main UNIX derivates. The reengineered system preserves computational models from RODOS, adding a powerful GIS support and applying modern database technologies with flexible configuration possibilities. Furthermore, these new GIS functionalities allowed implementing advanced simulation models for simulating countermeasures in inhabited areas (ERMIN - European Model for Inhabited Areas) and food production systems (AGRICP Agricultural Countermeasure Program). Both simulation models have been part of the EURANOS project and represent state of the art modelling capabilities in their respective area.
\end{abstract}

\section{INTRODUCTION}

In the late 80th, following the Chernobyl accident, many countries started to develop decision support systems for the off-site nuclear emergency management. Starting with third European Framework Programme, the European Commission supported the development of RODOS (Real-time on-line decision support) (see [1] and [2]) that should be applicable all over Europe. One of the major objectives in the development of that system was to harmonise nuclear emergency management in Europe. In the first decade, the work concentrated in the development of models for the early phase of an emergency such as atmospheric dispersion and early countermeasure modelling. In 2000, the focus of the model development changed as the decision making team recognised more and more the importance of the later phase of an accident. With the EURANOS (European Approach to Nuclear and Radiological Emergency Management and Rehabilitation Strategies) project which started in 2004 as part of the European $6^{\text {th }}$ Framework Programme, the efforts were directed for the first time towards the late phase problems [3].

One of the lessons learnt from previous activities was the need to involve the end users from the beginning into the development process. This was realised by establishing the RODOS Users Group (RUG) aiming to influence the research activities from the beginning. Within the EURANOS project the decision was taken to completely re-engineer the RODOS system and make it a Java application to assure sustainability for its computational platform. The new realisation of RODOS was named JRODOS [4]. 


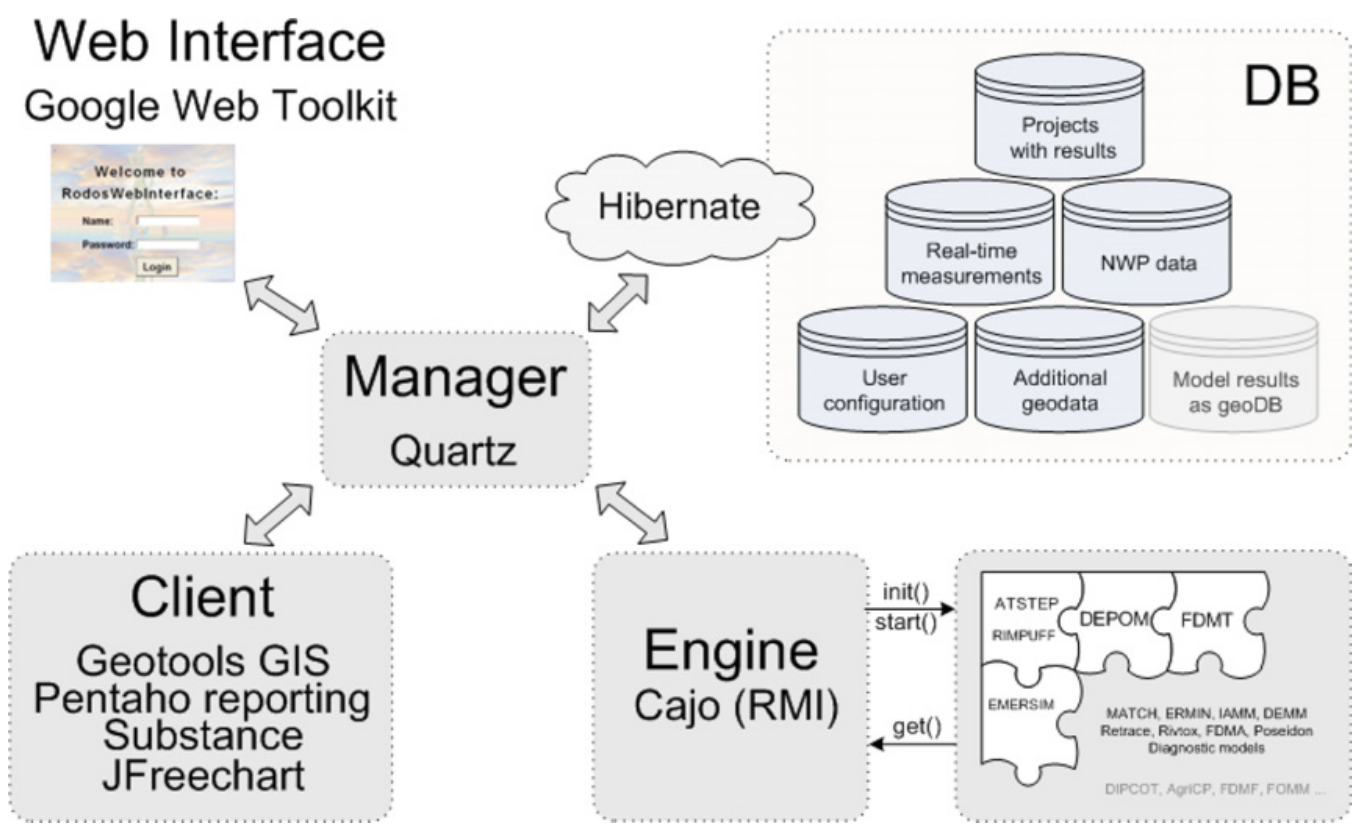

Figure 1. JRODOS Software design structure.

\section{JRODOS DEVELOPMENT}

The main objective of the RODOS users was to have a system that provides support in case of a nuclear or radiological accident anywhere in Europe. Further it should supports exercise preparation in addition to emergency management and can be made operational in all European countries (e.g. meets or can easily be adapted to national requirements). Finally it should be easy to operate (at least in certain core functionalities) and reliable in its use. Especially important were:

- User friendly and intuitive graphical user interface with low training requirements and easy, consistent and neatly arranged user input forms,

- Graphical representation of results that meets user requirements (e.g. integration of GIS functionalities, multi-lingual, annotated, etc.),

- Easy system administration and low maintenance costs.

In addition, the wish to integrate external simulation modules in an easy way emerged resulting in the idea to further develop the RODOS system into a framework with clearly defined interfaces e.g. for the simulation modules. This approach together with the requested GIS functionalities has built the basis for the development of the late phase countermeasure models. It was decided, different to the solution in RODOS, that the urban and agricultural areas should be separately modelled. As a consequence, the European Inhabited Area Model (ERMIN) and the Agricultural Countermeasure Program (AGRICP) were developed for inhabited areas and food production systems, respectively.

The basic software design of JRODOS is shown in Figure 1. It has been realised as a distributed system with different locations for the data bases and the simulation models. It allows also a realisation as a client server distribution where the data management and the computational models are placed in one powerful server whereas the user interfaces are located on thin clients. Furthermore, the user interface is also available as web application which allows using the system remotely with a similar look and feel as operating the main user interface on a local workstation. This realisation, however, is up to now limited to the early phase models but might also include the later phase models AGRICP and ERMIN in future. 


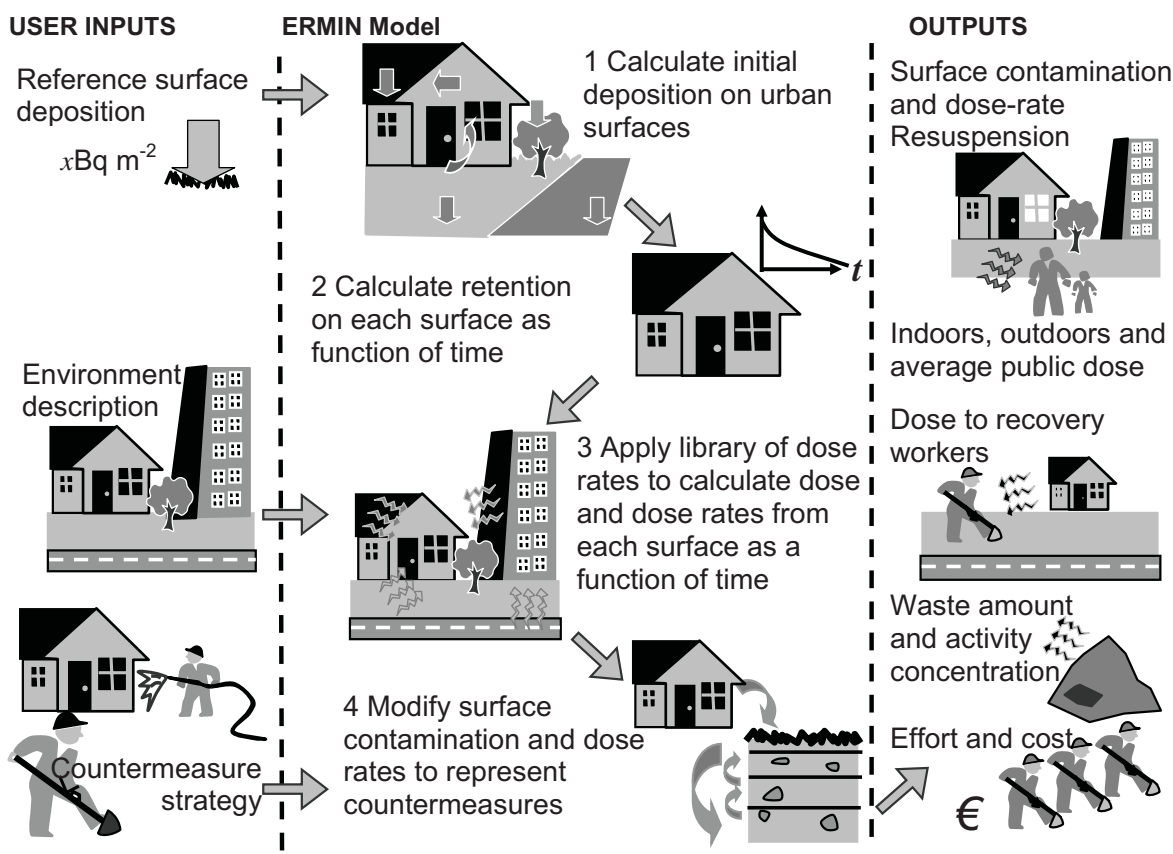

Figure 2. Stages of the ERMIN model calculation.

\section{INHABITED AREA MODEL ERMIN}

ERMIN was designed to assess doses and behaviour of radionuclides in inhabited environments [5]. The design was driven by user experience. One major issue from the past was the fact that decision makers often address recovery issues by sub-dividing the area of concern on the basis of, for example, land use, deposition level and emergency actions. Furthermore, the decision makers need to evaluate combinations of countermeasures. To achieve this flexibility, the operator had to interact with the model intensively. This was realised within ERMIN in the structure shown in Figure 2.

The most important aspect in the realisation of ERMIN was the possibility to add countermeasures in a flexible way into one countermeasures strategy. This was realised by implementing a simulation model that calculates the time dependent behaviour of radionuclide on the different surfaces including migration into the soil. Simulating the time dependency explicitly makes it now possible to combine countermeasures of any type and complexity within countermeasure strategy and for different areas in a different way (see Figure 3).

\section{FOOD COUNTERMEASURE MODEL AGRICP}

As for ERMIN, the users requested higher flexibility in the design and combination of individual countermeasures options. In the former Late Countermeasure Model Terrestrial (LCMT) [6], individual food countermeasures or selected combinations of two individual countermeasures were allowed. In the new model, any individual countermeasure can be combined with any other countermeasure with a user defined timing option. This flexibility was realised by implementing the countermeasure simulation inside the foodchain routines of the Foodchain and Dose Model Terrestrial (FDMT) [7]. 


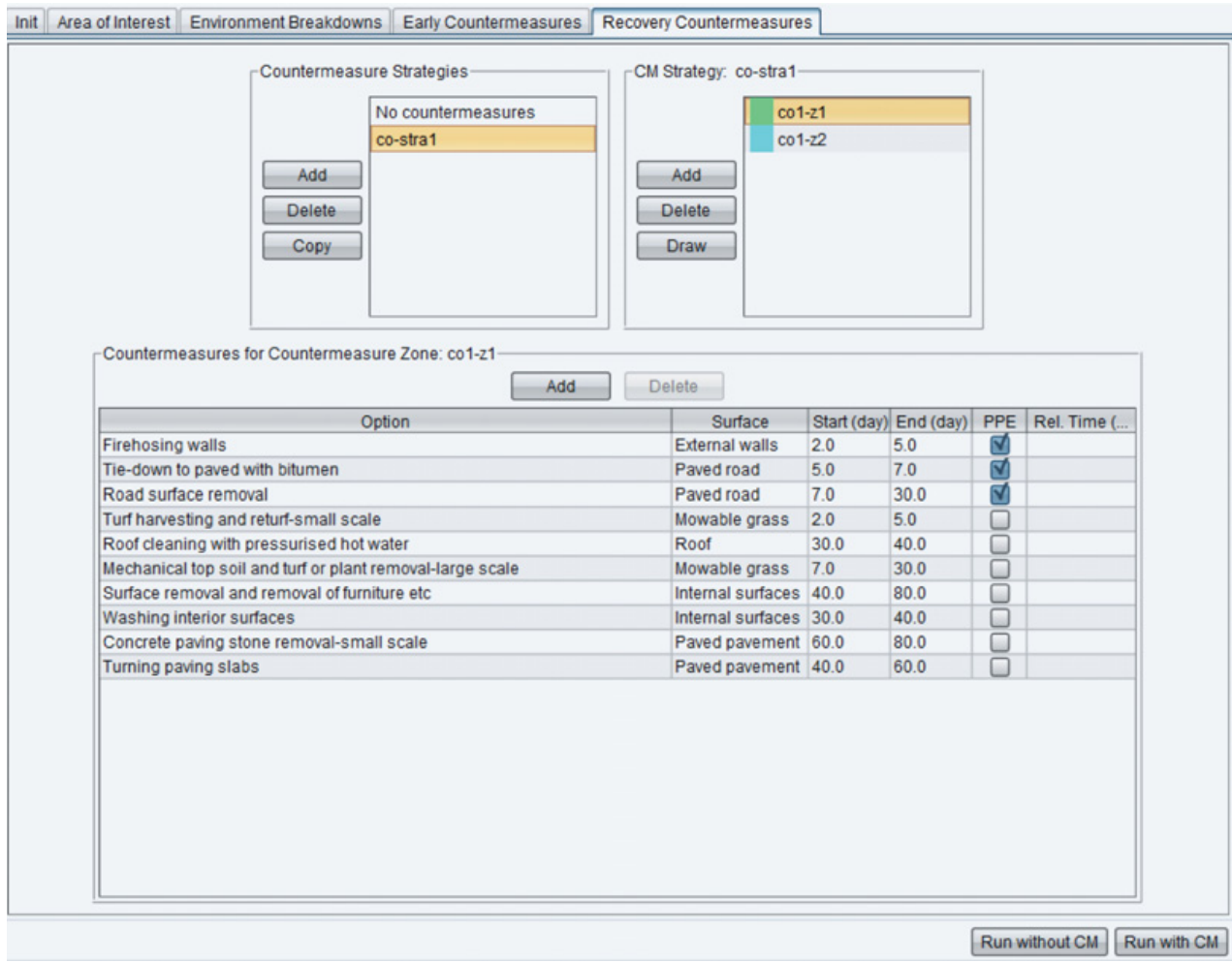

Figure 3. Design of a complex countermeasure strategy.

Countermeasures considered are

- Doing nothing,

- Food disposal or stopping production,

- Food processing,

- Storing food,

- Removing animals from contaminated feed $(\mathrm{t}=0)$,

- Removing animals from contaminated feed $(t>0)$,

- Supplementing animals feed with clean feed $(t=0)$,

- Supplementing animals feed with clean feed $(t>0)$,

- Substituting of animals feed with other contaminated feeds,

- Addition of sorbents/Boli,

- Amelioration,

- Change in land use,

- Change of crop species or variety.

To realise them, for example food processing options, modification of the animal's diet, transfer factors soil-crop, animal-animal product and reduced contamination in the soil were explicitly modelled according to the specification of the countermeasure timings.

Furthermore, the user interface of AGRICP and ERMIN should have the same look and feel which was realised in JRODOS. Figure 4 shows a complex example of a food countermeasure strategy that can be considered by the simulation model.

With the possibility to define further zones for countermeasure strategies, the drawback from the former LCMT has been completely removed. 


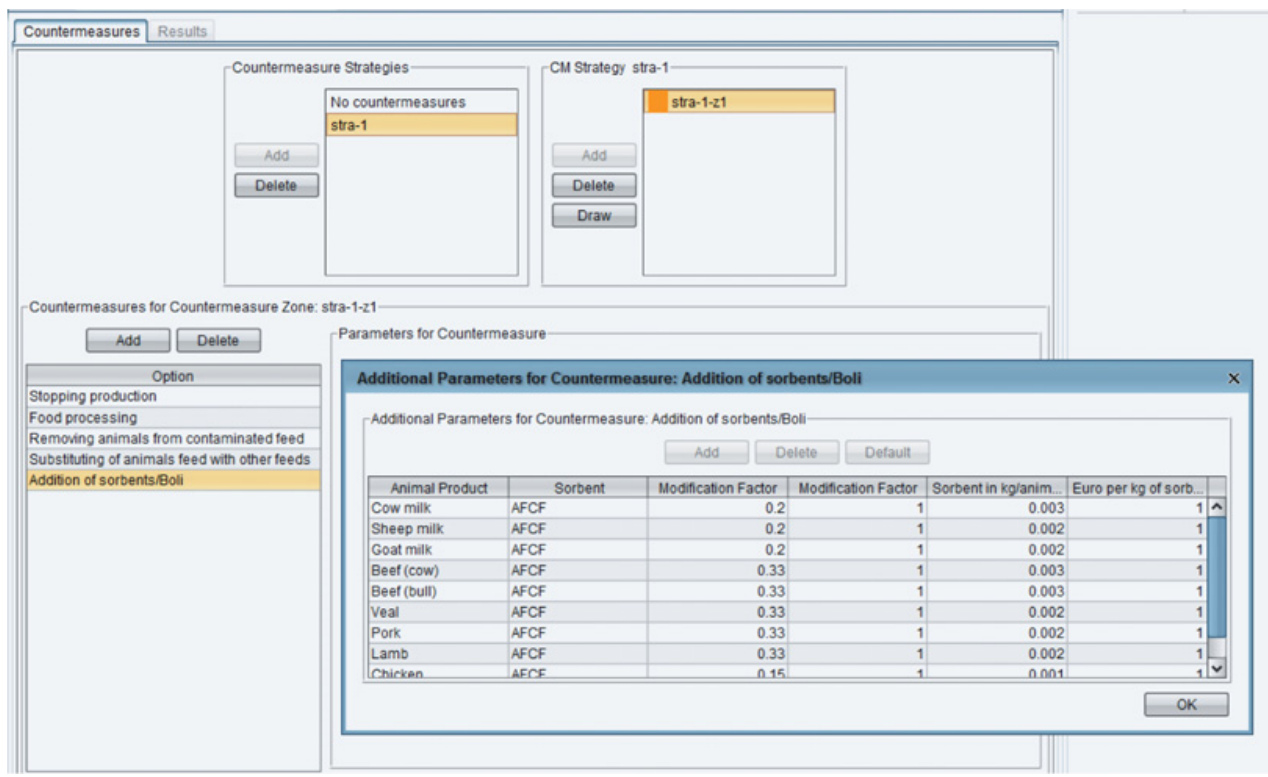

Figure 4. Countermeasure strategy for AGRICP.

\section{CONCLUSIONS AND FURTHER DEVELOPMENT}

The Java based RODOS System JRODOS has been realised as a flexible tool that allows a simple user interface for the early phase models but on the other side has enough capabilities with the implemented GIS to allow the definition of complex countermeasure strategies for late phase models in both the inhabited areas and the food production systems. With the two models ERMIN and AGRICP, the end users requests were realised and both models have been successfully implemented in JRODOS within the EURANOS project.

Having reached their objectives, some further necessary tasks were identified at the end of the EURANOS project. This included besides radiological emergency the fact that the new ICRP 103 recommendations, issued in 2007, followed by ICRP 109 on emergencies and ICRP 111 on recovery, were not adequately addressed in the simulation programs. So far the simulation models address particular countermeasures individually and do not include an integrated approach that is requested by the new ICRP approach. As the ICRP recommendations will become part of the EC safety standards in future there is a clear need to improve current modelling. Therefore the NERIS-TP project has started February 2011 to improve the models inside decision support systems related to the new ICRP recommendations.

One important aspect of these new ICRP recommendations is the optimisation of the countermeasure strategies to reduce the dose below a pre-defined reference level. ICRP recommends various dose numbers, however, optimisation might be also carried out below predefined reference levels. To deal with this, ERMIN and AGRICP will be enhanced with an optimisation wizard that guides the user through the many possible countermeasure options to select those which might be best in that given situation. The optimisation wizard will be realised as a knowledge data base which contains information from the European handbooks for managing contaminated food production systems and inhabited areas in Europe [8]. In this respect, the two simulation models will be further refined and made more and more user friendly. 


\section{Acknowledgments}

This work has received partial financial support from the European Commission Sixth Framework Programme (Nuclear Fission/Radiation Protection) under the EURANOS integrated project: European approach to nuclear and radiological emergency management and rehabilitation strategies (Contract No: FI6R-CT-2004-508843).

\section{References}

[1] Ehrhardt, J. and Weis, A. (eds), (2000), RODOS: Decision Support System for Off-site Nuclear Emergency Management in Europe. European Commission, Brussels, Report EUR 19144

[2] Raskob, W., Ehrhardt, J. (2000) The RODOS System: Decision Support for Nuclear Off-site Emergency Management in Europe. 10th International Congress of the International Radiation Protection Association, May 14-19, 2000, Hiroshima, Japan, CD

[3] Raskob, W., Gering, F., Lochard, J., Nisbet, A., Starostova, V., Tomic, B. (2010) Overview and main achievements of the EURANOS project: European approach to nuclear and radiological emergency management and rehabilitation strategies. Raskob, W., Hugon, M. (eds.): Enhancing Nuclear and Radiological Emergency Management and Rehabilitation, Key Results of the EURANOS European Project, Radioprotection Vol. 45, 2010, No 5, Supplement, pp. S9-S22

[4] Ievdin, I., Trybushnyi, D., Zheleznyak, M., Raskob, W. (2010) RODOS re-engineering: aims and implementation details. Raskob, W., Hugon, M. (eds.): Enhancing Nuclear and Radiological Emergency Management and Rehabilitation, Key Results of the EURANOS European Project, Radioprotection Vol. 45, 2010, No 5, Supplement, pp. S181-S189

[5] Charnock, T.W. (2010) The European model for inhabited areas (ERMIN) - developing a description of the urban environment. Raskob, W., Hugon, M. (eds.): Enhancing Nuclear and Radiological Emergency Management and Rehabilitation, Key Results of the EURANOS European Project, Radioprotection Vol. 45, 2010, No 5, Supplement, pp. S55-S61

[6] Brown, J., Smith, K. R., Mansfield, P., Smith, J. (1997) Models for decontamination, relocation and agricultural countermeasures in RODOS. Radiation Protection Dosimetry Vol. 73, 1997, No 1-4, pp. 75-79

[7] Müller, H., Bleher, M. (1997) Exposure pathways and dose calculations in RODOS: improvement of predictions by measured data. Radiation Protection Dosimetry Vol. 73, 1997, No 1-4, pp. 61-66

[8] Nisbet, A. et al. (2010) Decision aiding handbooks for managing contaminated food production systems, drinking water and inhabited areas in Europe. Raskob, W., Hugon, M. (eds.): Enhancing Nuclear and Radiological Emergency Management and Rehabilitation, Key Results of the EURANOS European Project, Radioprotection Vol. 45, 2010, No 5, Supplement, pp. S23-S37 